\title{
A CRITICA DE M. LESCURE A0 MEU ILLUSTRE MESTRE DR. ALMEIDA NOGUEIRA.
}

$\mathrm{Na}$ "Revue d'Economie Politique" de 1914, pag. 117, fez o notavel economista francez M. Jean Lescure, a critica do Curso Didactico de Economia Politica ou "Sciencia do Valor", de meu saudoso mestre Dr. Almeida Nogueira.

Apezar de ser essa critica elogiosa, não concordo com ella em alguns pontos, motivo por que ouso escrever este artigo, defendendo o meu Mestre e preclaro economista patrio, Dr. José Luiz de Almeida Nogueira.

Minha ousadia é grande, bem sei.

Mas tendo um autor estrangeiro, por mais notavel que seja, criticado a obra de um dos maiores economistas brasileiros, que na Cathedra de Economia Politica da Faculdade de Direito de S. Paulo brilhou, discutindo os mais arduos problemas economicos, economista que me iniciou, como mestre, na Sciencia Economica, e estando hoje impossibilitado de se defender, arrancado á vida e á Patria pela morte impiedosa, na plenitude de seu genio, quando ainda tantas liçóes poderia dar aos estudiosos, e tantos serviços prestar á nossa terra querida, a mim, seu admirador sincero, compete empunhar a penna, e responder ás criticas feitas á sua magnifica obra, cumprindo assim um dever de gratidão, um dever de patriota.

Concordo com M. J. Lescure, quando diz: "Ce traité d'économie politique, en deux volumes, publié por M. Almeida Nogueira, professeur d'économie politique á la $\mathrm{Fa}$ culté de droit de S. Paul, présente de trés grandes qualités:

7-Revista F: D. 
d'abord pour un cours didactique, une trés grande clarté dans le plan, dans la division, dans les définitions, dans l'exposition. Et M. Almeida Nogueira, a rendu assurément á l'économie politique un service important en publiant ce traité écrit en langue portugaise. Car, et c'est là son principal mérite, a notre sens, il sera désormais possible aux étudiants de langue portugaise d'apprendre l'économie politique dans un bon traité écrit dans leur langue."

Ainda concordo no ponto em que diz: “M. Almeida Nogueira, est, en effet, très au courant des questions é conomiques d'ordre théorique ou d'ordre pratique."

Com effeito meu grande e saudoso mestre, Dr. Almeida Nogueira, era homem de extraordinario talento e espantosa cultura, ajuntando a estes predicados o éstylo agradavel e a harmonia intellectual, que são privilegio da raça franceza, cuja cultura e cujo espirito tão bem assimilou, quando fez seus estudos em Paris, onde esteve muitos annos, havendo completado a sua educação com dous professores franceses, na fazenda de seu pai, o Barão de Joatinga.

Orador eloquente e sobrio, á ingleza, conhecendo todos os sports, profundo e notavel occultista, literato, historiador, philosopho, jurisconsulto, parlamentar, etc., foi grande em todos os ramos dos conhecimentos humanos.

$\mathrm{Na}$ exposição era clarissimo, e imprimia ás suas sábias lições um cunho agradavel pela amenidade do estylo, realçada pela sua figura sympathica, amavel e bondosa.

Como homem, caracterizou-o bem o Dr. Wenceslau de Queiroz: era um forte e um bom, "vir fortis et fidelis."

Como scientista, foi verdadeiramente espantoso, não só apreciado por sua erudição, 'segundo linhas acima dissémos, mas ainda encarado do ponto de vista da capacidade de trabalho, na qual foi insuperavel, pois escreveu sobre quasi todos os ramos das sciencias juridicas e sociaes, achando ainda tempo para fazer interessantissimas investi- 
gações historicas, e tratar de outros assumptos, sempre com a mesma perfeição.

Investigador, chegou quasi á mania, e todos que se entregam entre nós (são bem poucos...) ás investigações historicas, sabem quanta difficuldade temos para obter informações e documentos, lutando com a má vontade dos ignorantes, e com a guerra mesquinha dos presumpçosos.

Todos os obstaculos superou elle, e legou-nos as "Tradições e Reminiscencias", maravilha de saber, joia literaria, titulo bastante de gloria para um escriptor. Para elogio de seu amor ao trabalho, basta dizer que ainda escrevia e investigava nos dias que antecederam á sua morte.

Mas, reconhecendo muitas destas grandes qualidades do meu saudoso e notavel Mestre, faz M. Lescure á sua obra algumas criticas, que julgo sem razão de ser, e emitte algumas apreciações, com que não concordo.

Em primeiro lugar critica o modo de dividir a Economia Politica, seguido por meu illustre Mestre, concluindo: "...ce plan peut, en effet, se défendre."

Ora, deixando de parte qualquer consideração philosophica sobre a divisão da sciencia, cousas para nós, agora ao menos, de pouca importancia, diremos que M. Jean Lescure não deveria ter feito semelhante affirmação.

No tit. 1, cap. $4 .^{\circ}$, ed. de 1918, trata o Dr. Almeida Nogueira da divisão do estudo da Economia Politica, e mostra a difficuldade do assumpto e as divergencias entre os escriptores.

E como não ser assim se encaram elles differentemente os complexos phenomenos economicos?

No cit. cap. $4 .^{\circ} \mathrm{V}$, n. 363 , indica o systema que seria coherente com a doutrina de Macleod.

No n. 369, explica o meu illustre Mestre que limitada liberdade exerceu na disposição methodica das materias de sua obra, pois, destinando-se o seu livro a compendio, não 
podia alardear feição innovadora, mas deveria seguir o consagrado pela tradição escolar.

O fim que se propoz o meu saudoso Mestre foi o mesmo de Colson, que, como veremos, julga M. Lescure ignorada pelo meu illustre Mestre.

Explica Colson: "La seule prétention qu'on puisse avoir, quand on présente un cours complet d'Economie $\mathrm{Po}_{0}$ litique sous un volume aussi restrein, c'est de mettre le lecteur qui voudrait, ensuite, étudier á fond tel ou tel point, en situation de le faire, sans oublier aucun des éléments essentiels de la question ou de ses tenants et aboutissants. Tel est le but que j'ai cherché à atteindre et c'est cette preoccupation qui me servira d'excuse, pour l'insuffisance des explications contenues dans les passages trop nombreux ou j'ai été obligé d'indiquer, par une affirmation sommaire des idées ou des faits qu'il été bon d'appuyer de preuves étendues, si ces preuves avaient pu trouver place dans des; leçons aussi limités."

E' por conseguinte infundada a critica de M. Jean Lescure.

E porque não seguir o Dr. Almeida Nogueira, a divisão que adoptou?...

Já foi feita, por algum economista, uma divisão melhor ou menos imperfeita?...

A resposta não póde deixar de ser negativa.

N. G. Pierson, (1905), trad. de Erasmo Malagoli, depois de advertir que a divisão que adopta differe da usual, diz: "E' vero che ci sono quasi tante partizione dell'Economia politica, quanti sono i Trattati, (p. 40, v. 1).

Temos as divisões originaes propostas por Pantaleoni (1889), V. Paretto, Camillo Supino, Augusto Graziani (1904), perfeitamente conhecidas por Almeida Nogueira, que tinha lido todos estes tratados, e mesmo citou não só Pierson, mas tambem Cossa, que tem um bello capitulo sobre a materia.

\section{UNIVERSIDADE DE SÃO PAULO}

Departamento de Cultura e Ação srint

Biblioteca Central 
Fez bem Almeida Nogueira adoptando o plano que se vê em sua obra, justificando-o com as sensatas palavras seguintes: "O plano pois que havemos adoptado para este trabalho ao passo que se não distancia da tradicional propedeutica economica, exprime, attenta a nossa escola, uma transacção. Esta, porém, limita-se a concessões meramente formaes; porque, quanto ao fundo doutrinario, resalvamos integra a nossa autonomia intellectual."

Nas escolas, nas Faculdades, não é vantajoso fazer grandes innovações. Ha interesse para os alumnos em ser o professor algum tanto conservador.

Muito melhor andaria M. Lescure, não tocando neste ponto, onde será silenciado pela verdade.

Diz, em 2. ${ }^{\circ}$ lugar, M. J. Lescure: "Toute-fois, si le cours de. M. Almeida Nogueira se recommande sans réserve en tant qu'ouvrage purement didactique, on doit reconaitre que l'auteur, et c'est d'ailleurs là autant un eloge qu'une critique, n'a point la prétention d'apporter une contribuition originale en notre matière. Il s'est très bien assimilé nos ouvrages d'économie politique même les plus récents. Et c'est ainsi qu'il a reussi á écrire un manuel clair, précis et fort utile."

Em relação á originalidade, repetirei, não podia ser original o autor em um livro didactico, sem pretenção innovadora, conforme confessa o proprio autor.

Quanto ao Dr. Almeida Nogueira ter aprendido a Economia Politica nas obras francesas, é um engano.

Conhecendo proffundamente a literatura economica da França, dos Estados Unidos, da Italia, da Allemanha e dos diversos paizes europeus e americanos, foi beber os seus principios particularmente nas obras de Macleod, cuja escola inovadora seguiu (v. $1 .^{\circ}$, p. 8, Prefacio).

Comtudo, espirito liberal, alma generosa, grande coração, não levava a extremas consequencias o principio individualista (Pref., cit.) 
Dahi as suas contradicções com o Mestre, com Mecleod, o grande economista escossez. Em muitos pontos de sua obra, como fiz notar na minha these sobre "Salario", pende para o Socialismo.

$\mathrm{Na}$ Bibliotheca da Faculdade, existem as obras de Macleod, no original, lidas e annotadas pelo meu saudoso Mestre.

Vejamos agora, finalmente um lamentavel engano de M. J. Lescure.

Finaliza M. J. Lescure a sua apreciação com as seguintes palavras: "Signalons-lui cependant une grosse lacune: il ignore le cours de M. Colson, certain qu'il la comblera rapidement."

Adoça a observação com os seguintes cumprimentos: ... "Félicitons l'auteur d'avoir réussi dans une tache où il eut été si facile d'échouer."

Ora, mostrarei o erro de J. Lescure, fazendo levianamente tão grave accusação.

No cap. III, tit. I, pag. 98, cita, Almeida Nogueira, a obra de Colson. Na pag. 99, cita novamente a obra de Colson, a proposito da escola classica.

Cita ainda a obra de C. Colson na pag. 108, a proposito do Socialismo Christão.

Ahi temos Almeida Nogueira citando a obra de Colson, que desconhece!

Nem se diga que citava sem ter lido. Almeida Nogueira, como se poderá ver em sua obra, cita os lugares precisos em que leu a obra conhecidissima de C. Colson, "Ingenieur en Chef des Ponts et Chaussées, Conseiller d'E'tat, Paris, 1901, Cours d'E'conomie Politique, professé à l'école nationale des Ponts et Chaussées." Colson .

Ainda ha um ponto que faz sobresahir a leitura de

Colson e Almeida identificam ou confundem, propositalmente, o Socialismo de Estado e o Socialismo de Cathedra . 
Da citação de Almeida Nogueira, pag. 108, ao tratar de Socialismo, concluimos que elle se guiou no assumpto pela obra de Colson.

Diz Colson: "Le Socialisme d'Etat, qu'on appellait le Socialisme de la Chaire quand il prit maissance dans les Universités Allemandes, etc." (P. 27, v. 1).

A mesma indentificação ou confusão faz Almeida Nogueira:

"Tem se denominado Socialismo de Cathedra, Socialismo professoral, socialismo de Estado e tambem socialismo conservador à uma escola economica com laivos de socialismo, iniciada na Allemanha na mesma época e com o mesmo criterio que a escola historica na sciencia do Direito, compostas ambas, de Professores das Universidades daquelle paiz." (P. 106, v. $1 .^{\circ}$ ).

Como ensina A. Wagner, ha differença entre Socialismo de Cathedra e de Estado, e o mesmo Wagner é que vai nos dizer por que é que Almeida Nogueira e Colson, confundem as duas escolas, muito de conformidade e usando quasi das mesmas palavras.

Falando do Socialismo de Estado, diz Adolph Wagner, trad. de Polak, (1904). "Les Fondements de l'E'conomie Politique:" On désigne ainsi des tendences très diverses. Cependant les adversaires ont simplement identifié le socialisme d'E'tat avec le Socialisme de la Chaire; c'est une inexactitude qu'il faut rectifier." E explica: "D'après ce qui a été dit, le Socialisme de la Chaire n'est pas en somme un concept, simple, ce n'est pas même un concept, c'est un non collectif embrassant diverses tendances toutes hostiles à l'individualisme économique pur. Si cependant le mot repondait à in concept il serait beaucoup plus large que celui de Socialisme d'E'tat, qui est bien une des nombreuses tendances du Socialisme de la Chaire mais une tendance très peu répandue jusqu'aujourd'hui" (pag. 82). 
Por ahi vemos que se distinguem perfeitamente o socialismo de Estado e o socialismo de Cathedra.

Vemos tambem o grande Mestre Almeida Nogueira, seguindo a lição de C. Colson, e dos adversarios do socialismo, confundindo, ou melhor identificando, o socialismo de Estado e o de Cathedra.

Como poderia Almeida Nogueira tirar idéas de Colson, se ignorava o seu curso?...

Nem se diga que o meu illustre Mestre confundia as duas noções por ignorancia: não!

Conhecia perfeitamente os trabalhos de Wagner e dos mais illustres socialistas, mas... era macleodista! Filiado a uma escola insustentavel, teve que defendel-a com o seu grande talento.

Mas, como fiz notar, no começo deste modesto artigo e na minha these sobre "Salario", faz elle varias concessões, fugindo da doutrina estreita de Macleod.

Não cabe aqui a explicação do que seja o socialismo, das differentes especies de Socialismo Scientifico, nem das divergencias de escola que tenho com Almeida Nogueira, assumpto de que me occuparei proximamente em uma conferencia sobre "Socialismo Harmonico", a nova escola economica por mim fundada, lançando eu as suas bases na minha these sobre "Salario", que mereceu o elogio dos maiores economistas da França, da Italia e do Brasil.

Mas, duas forças oppostas actuavam no espirito de Almeida Nogueira: seu liberalismo, sua caridade, sua intelligencia, sua humanidade, de um lado; o habito e o preconceito, de outro.

O Brasileiro tem ainda horror ao socialismo, razão por que o grande escriptor temia manifestar as suas tendencias socialistas, ás quaes mostra decidida sympathia em varios pontos de sua obra. Agia assim sensatamente, não rompendo radicalmente com a rotina, não atacando 
de frente os preconceitos vulgares do povo ignorante e dos scientistas presumidos.

Queria eu chegar ao ponto seguinte: Almeida Nogueira foi beber suas idéas, neste capitulo, em Colson, cuja obra cita tres paginas adiante (pag. 108). Como dizer, pois, que Almeida Nogueira ignorava o curso de Colson?... Julgo ter provado á saciedade que Almeida Nogueira conhecia perfeitamente a obra de C. Colson, por elle tantas vezes citada.

Ficam, assim, rebatidas as criticas que M. Jean Lescure fez, imprudentemente, ao meu saudoso e querido Mestre, o grande economista J. L. de Almeida Nogueira, cuja obra leu M. Lescure, seguramente com attençãı menor do que a devida a esse notavel trabalho.

S. Paulo, Janeiro de 1918.

Braz de Sousa Arruda. 